\title{
IS ORGANIC AGRICULTURE MORE SCALE EFFICIENT THAN CONVENTIONAL AGRICULTURE? THE CASE OF COCOA CULTIVATION IN GHANA
}

\author{
Justice Gameli DJOKOTO $^{* 1}$ (iD), Victor OWUSU ${ }^{2}$ (iD), Dadson AWUNYO-VITOR ${ }^{2}$
}

\author{
Address: \\ ${ }^{1}$ Central University, Central Business School, Department of Agribusiness Management, Box DS 2310, Dansoman, \\ Accra, Ghana. \\ ${ }^{2}$ Kwame Nkrumah University of Science and Technology, Department of Agricultural Economics, Agribusiness and \\ Extension, Kumasi, Ghana. \\ * Corresponding author: dgameli2002@gmail.com
}

\begin{abstract}
Research background: Despite the growing social recognition of the positive role played by organic farming in the conservation of natural resources and the reduction or elimination of the negative externalities of modern agriculture, the economic competitiveness of organic versus conventional agriculture is a contentious issue. Studies on scale efficiency in the agricultural economics literature, in general, did not address the differences in production practices such as organic and conventional production.

Purpose of the article: We estimated scale efficiency of organic and conventional production, tested for differences between organic and conventional agriculture scale efficiency, and explored the sources of inefficiencies.

Methods: This was accomplished using cross-sectional data on 658 organic and conventional cocoa farmers, for the 2012/13 production season in the Eastern Region of Ghana. The analysis accounted for selection bias and recognised the fractional property of the scale efficiency measure.

Findings \& Value added: Organic agriculture is less scale efficient than conventional agriculture. Whilst we recommend that both producer groups improve scale efficiency, organic producers require greater work to do to make up for the almost $50 \%$ scale inefficiency. We also found farmer-based organisations to significantly influence scale efficiency. This calls for the need to strengthen farmer-based organisations to increase participation, among other reasons. We departed from the existing scale efficiency literature in a three of ways. We accounted for selection-bias using propensity score matching in the organic and conventional samples in analysing scale efficiency, modelled scale inefficiency using fractional regression and empirically selected the appropriate link function using a battery of tests. Finally, we accounted for an important policy variable; farmer-based organisation. We employed propensity score matching that accounted from observable biases. Further research may consider other methods that account for both observed and unobserved variations.
\end{abstract}

Key words: conventional cocoa; organic cocoa; fractional regression; scale efficiency; selection-bias JEL: C21; D24; Q12; Q29

\section{INTRODUCTION}

In food production, the fertilisation and accomplishment of other agronomic practices, using chemicals has become conventional practice around the world. However, a move towards organic agriculture $(\mathrm{OA})$ has emerged. This involves maximum reliance on self-regulating ecological or biological processes and renewable resources. OA makes systematic efforts to reduce reliance on external inputs partly to create a sustainable agricultural production system (Paull, 2013; Beltrán-Esteve and ReigMartínez, 2014). Despite the growing social recognition of the positive role played by this type of farming in the conservation of natural resources and the reduction or elimination of the negative externalities of modern agriculture, the economic competitiveness of organic versus conventional agriculture is a contentious issue (Beltrán-Esteve and Reig-Martínez, 2014; 2016). Whilst the dimension on efficiency holds that; OA is more technically efficient than conventional agriculture (CA) (Oude Lansink et al., 2002; Poudel et al., 2015), there is counter-evidence, that, OA is more technically inefficient than CA (Madau, 2007; Tiedemann and LataczLohmann, 2013). The latter has been attributed to restrictions on resources and technology, emanating from regulations and guidelines governing OA (IFOAM, 2008, 2014; Mayen et al., 2010; Beltran-Esteve and ReigMartinez, 2014; Lakner and Breustedt, 2016).

Productivity (efficiency) change depends partly on scale of operation (Ray, 1998; Rasmussen, 2010), the effectiveness of which is measured by scale efficiency and how close an observed firm or farm unit is, to the optimal scale (Ray, 1998; Karagiannis and Sarris, 2004). In the light of the contention regarding organic and conventional technical efficiency, would OA be more scale inefficient than CA or otherwise?

We address this research question by estimating scale efficiency (SE) of organic and conventional agriculture, 
test for differences between organic and conventional agriculture, and explore the sources of inefficiencies, using data on organic and conventional cocoa production in Ghana.

Studies on SE in the agricultural economics literature, in general, did not address the differences in production practices; organic and conventional production (Bremmer et al., 2008; Madau, 2011; Mgeni and Henningsen, 2012; Kelly et al., 2013; Watkins et al., 2014). Only, Karagiannias et al. (2012) did. However, they failed to account for selection bias. While some studies did not model SE at all (Pantzios et al., 2002; Karagiannis and Sarris, 2004; Hussiani and Abayomi, 2010; Karagianni et al., 2012; Baran, 2013; Karagiannis and Melfou, 2015), others that modelled SE, did not appropriately account for the fractional property of SE estimates (Paul et al., 2004; Sengupta and Kundu, 2006; Bremmer et al., 2008; Madau, 2011, 2015; Kelly et al., 2013). Rahman and Awerije (2015) is an exception, yet they specified logit a priori and did not empirically select the appropriate link function.

This article departs from other SE studies in three ways. First, it takes account of selection bias in the organic and conventional samples. Second, SE is parametrically modelled, using fractional regression with an empirical selection of the appropriate link function of the fractional regression model. Finally, we accounted for an important policy variable; farmer-based organisations.

Conventional cocoa production involves the use of inorganic fertilisers, chemical weed control as well as chemical pest and disease control. On the contrary, organic production bars the use of these. Alternatives may involve manual and operations that could limit the size of a farm operation to be undertaken by organic cocoa farmers (Paull, 2013; Beltrán-Esteve and ReigMartínez, 2014). Thus, scale efficiency has implications for input use, revenue, cost and ultimately the profitability of farm operations. For organic farmers who have adopted new production technology with associated management practices that could affect optimal farm size, which may differ from conventional farmers, it is important to compare the scale efficiency of organic and conventional cocoa farms. Results of this study will establish what the scale efficiency of organic farms is, how it differs from conventional cocoa farms and what policy recommendations will be apt.

\section{DATA AND METHODS}

\section{Data}

Cocoa farmers were sampled from Suhum-Craboa-Coalter (SCC) district in the Eastern Region of Ghana, because at the time of data collection in 2014, only farmers in this area had practised organic cocoa production in Ghana, for a decade after certification. The district falls within the semi-equatorial forest zone and experiences a major (March to June) and a minor (September to October) rainy season. The temperature varies between 24 and $290 \mathrm{C}$, and the annual rainfall is between 1270 and $1650 \mathrm{~mm}$ (Abekoe et al., 2002; Ayenor et al., 2004). SCC has a total land area of about $850 \mathrm{~km}^{2}$, with $20 \%$ of this area under cocoa cultivation, contributing more than 500 metric tonnes of beans (YGL, 2008).

Two populations were defined; growers of conventional cocoa and growers of organic cocoa. Ten thousand organic cocoa farmers were operating in the SCC District as of 2014, according to the Yayra Glover Limited (YGL), the firm that facilitates organic cocoa production in the study area. The Cocoa Health and Extension Division (CHED) of COCOBOD, responsible for extension services to cocoa farmers, put the number of conventional cocoa farmers in the district at 18,425. From these populations, the sample size of organic and conventional farms was determined to be 278 and 378 respectively.

Twenty-six and 37 communities respectively, in which organic and conventional cocoa farmers resided were selected. For the organic cocoa community, 26 farmers were selected whilst 12 farmers were selected for conventional cocoa based on the number of communities in the sampling frame. The total respondent targeted for each production technology was approximately $10 \%$ above the determined sample size, to make room for nonresponse. A pre-tested questionnaire was administered with the assistance of Agricultural Extension staff from CHED. Returned and usable questionnaires for organic and conventional cocoa producers were 280 and 378 respectively.

The specific conventional communities were same as those of the organic, where possible, or closest to organic cocoa communities, to control for environmental differences and have analogous sample composition (Tzouvelekas et al., 2002; Madau, 2007; Guesmi et al., 2012). A cocoa farm was operationalised as a crop farm that has more cocoa plants than any other cultivated plant in the field. For organic farms, these were certified as organic and organic practices were applied to the other plants in the same field, with the cocoa plants.

\section{Methods}

\section{Production function}

The production functions were estimated by Stochastic Frontier Analysis (SFA), owing to the inherent stochasticity in the model, which is akin to stochasticity in agricultural production (Kumbhakar and Lovell, 2000, Mayen et al., 2010; Djokoto, 2016), with a composed error term (Aigner et al., 1977 and Meeusen and van den Broeck, 1977). The production function was specified as Eq. 1.

$y=f(X, \beta) e^{v-u}$

Where: $\boldsymbol{y}$ represents output, measured in kilogrammes; $\mathbf{X}$ is a vector of production inputs. In our case, farm size (ha) is FARMSIZE, labour (man-days) is LABOUR and tree age (years) is FARMAGE, as in Table 1. Possible omitted variable bias is addressed later.

$\boldsymbol{\beta}$ is a vector of parameters we estimated, $v$ and $u$ are error terms. The frontier production function is a measure of the maximum potential output attainable given the production inputs. Both $v$ and $u$ cause actual production to deviate from this frontier. The random variable in the production that cannot be influenced by producers and 
captures omitted variables such as weather and represented by $v$, is identically and independently distributed (iid) as $N\left(0, \sigma_{\mathrm{v}}^{2}\right)$. The non-negative error term $u$ represents the deviation from the maximum potential output, attributable to technical inefficiency, which is independent of $v$. The stochastic terms $v$ and $u$ are assumed to be uncorrelated. We assumed the half-normal distribution of the errors.

We estimated both the Ordinary Least Squares (OLS) and SFA forms of the Cobb-Douglas (CD) and translog functional forms and selected the SFA translog form based on the loglikelihood ratio test. Important variables; fertiliser and pesticides were omitted from the variable list. In the case of the former, the series was collinear with the land. This is because the governments' fertiliser programme supplied fertiliser to farmers based on the size of the plot a farmer reported. Also, farmers who followed the recommended fertiliser application regimen related the fertiliser requirements to the size of the plot. For the latter, pesticide, the data for conventional was unreliable whilst organic farmers did not formally apply pesticides. These may lead to omitted variable bias (OVB) which we tested. Square and cubic powers of the prediction of output were included as additional explanatory variables in the production function. The joint significance of the parameters of the additional terms was performed (Ramsey, 1996).

\section{Selection-bias}

A three-step procedure was used in accomplishing PSM (Rosenbaum and Rubi, 1983; Imbens, 2004). In the first step, a probability model for the adoption of organic production standards was estimated and used to calculate the probability or propensity score of being organic, for each observation. In the second step, the required estimation of the stochastic frontier model on the unmatched sample was performed. In the third step, matching of the organic and conventional subsamples was performed. The reverse of step two and three was necessary to ensure that matching of the subsamples that could lead to data attrition does not negatively impact the frontier estimates (Mayen et al., 2010; Rao et al., 2012).

\section{Scale efficiency}

Following the specification of the production function in (1), we adopted the Ray (1998) approach to estimating the SE.

$S E_{i}=\operatorname{Exp}\left[\frac{\left(1-E_{i}\right)^{2}}{2 \beta}\right]$

Where: the elasticity of scale $\left(E_{i}\right)$ was computed as the sum of the first-order partial derivatives of the explanatory variables of the production function, evaluated at their mean values and $\beta$ is the sum of the coefficients of the cross terms.

$\beta$ was hypothesised to be negative definite, to be sure that $0 \leq S E_{\mathrm{i}} \leq 1$. Although negative definiteness of $\beta$ was sufficient condition, it was not a necessary condition (Ray, 1998). $E$ and $\beta$ are both equal to one, only at the most productive scale size (MPSS); the point where there are constant returns to scale (Ray, 1998). Indeed, when $x^{i}$, the input bundle itself is MPSS, then $E\left(x^{i}\right)=1$ and $\ln S E_{i}$ $\left(x^{i}\right)=1$. With increasing returns to scale, $E_{i}>1$ and $S E\left(x^{i}\right)$ rise with a rise in output. On the other hand, a farm that exhibits decreasing returns to scale or supra-optimal scale $\left(E_{i}<1\right)$, there should be a contraction in output for optimal scale to be achieved.

\section{Conventional and organic scale inefficiency effects}

Socio-economic variables; specifically farm and farmer characteristics offer an important avenue to identifying drivers of scale inefficiency (SIE). Since SIE is defined within the unit interval, we employed fractional regression modelling (Papke and Wooldridge, 1996), and selected the appropriate link function, from a set of plausible link functions.

Let the conditional expectation of $S I E$ given $x$, be $E(S I E \mid x)$, then

$E(S I E \mid x)=G(x \theta)$

where $G(\bullet)$, which is some nonlinear function satisfying $0 \leq G(\bullet) \leq 1$, could be any cumulative distribution function, such as logit, probit, loglog, complementary $\log \log$ (cloglog) and cauchit (Papke and Wooldridge, 1996; Ramalho et al., 2010). SIE is $1-S E$ and $x$ are farm and farmer characteristics. The link functions are specified in Eq. 4- Eq. 8.

Logit,

$G(x \theta)=\frac{e^{x \theta}}{1+e^{x \theta}}$

Probit,

$G(x \theta)=\Phi(x \theta)$

Loglog,

$G(x \theta)=e^{-e^{-x \theta}}$

Cloglog,

$G(x \theta)=1-e^{e^{x \theta}}$

Cauchit

$G(x \theta)=\frac{1}{2}+\frac{1}{\pi} \arctan (x \theta)$

The various link functions were estimated using frm (Ramalho, 2013, 2014).

Following Ramalho et al. (2010; 2014), three groups of tests were employed to select the appropriate link function; Ramsey RESET test (Ramsey, 1969), generalised goodness of functional form test (GGOFF) (Ramalho et al., 2014) and $P$ test (David and MacKinnon, 1981). The RESET test examined the presence of misspecification in the model, specifically, the presence or otherwise of power terms in the model. Although the RESET test was originally developed for use with linear functions, Pagan and Vella (1989), Ramalho et al. (2010, 2011) and Cameron and Trivedi (2013, p. 52) have shown that it is also applicable to any type of index models.

The GGOFF, tests for how well the data fit the link function specified. More than one link function could be selected by the RESET and GGOFF tests. Therefore, the $P$ test provided an opportunity for one-on-one (pairwise) test using the selected link function(s) from the first two stages, as alternative hypotheses. Interpretation of the $P$ 
test followed that of the usual hypothesis test, unlike the other two tests, for which the rejection of the $H_{0}$ was evidence of absence of misspecification. Statistical methods of selection offer a viable alternative, in the absence of a priori theoretical formulation of the appropriate functional form for the FRM.

\section{RESULTS AND DISCUSSION}

\section{Background of data}

The difference in years of education of 0.04 years and 0.02 members of household between conventional and organic cocoa farmers were so small to be statistically significant (Table 1). The strongest statistically significant differences related to farm age (FARMAGE), access to credit (CREDIACC), cocoa farming experience (FARMEXP), the incidence of CSSVD attack (CSSVD) and access to extension services (EXTNACCESS). On the contrary, the weakest statistically significant differences were participation in a farmer-based organisation (FBOPARTICIPATION), plot size (FARMSIZE), labour use (LABOUR), gender (GENDER) and age of farmer (FARMERAGE). Whilst the average age of organic cocoa farms was 29 years that for conventional farms was 18 years. Fewer conventional cocoa farmers had access to credit (19\%) than organic cocoa farmers (49\%). This is to be expected as credit is a determinant of organic cocoa technology adoption (Djokoto, Owusu and AwunyoVitor, 2016). Organic cocoa farmers have been farming on average for about 20 years whilst conventional cocoa farmers registered an average of 16 years.

\section{Omitted variables test}

Following the non-use of fertiliser and pesticide from the model, due to reasons adduced earlier, a test of omitted variables was performed (Table 2). The null hypothesis that power terms (other terms) in the test model were jointly significant, could not be rejected in the case of the organic sample. By implication, there are no omitted variables in the organic model, thus the exclusion of the fertiliser and pesticide variables did not have a discernible effect on the model. In the case of the conventional sample however, the $\chi^{2}$ test statistic is significant at the $1 \%$ level of significance. Impliedly, there is an omitted variable in the conventional model. The solution to omitted variables in the agricultural production function literature is to use financial variables (Apergis, 2007).

Table 1: Variables definitions and descriptive statistics

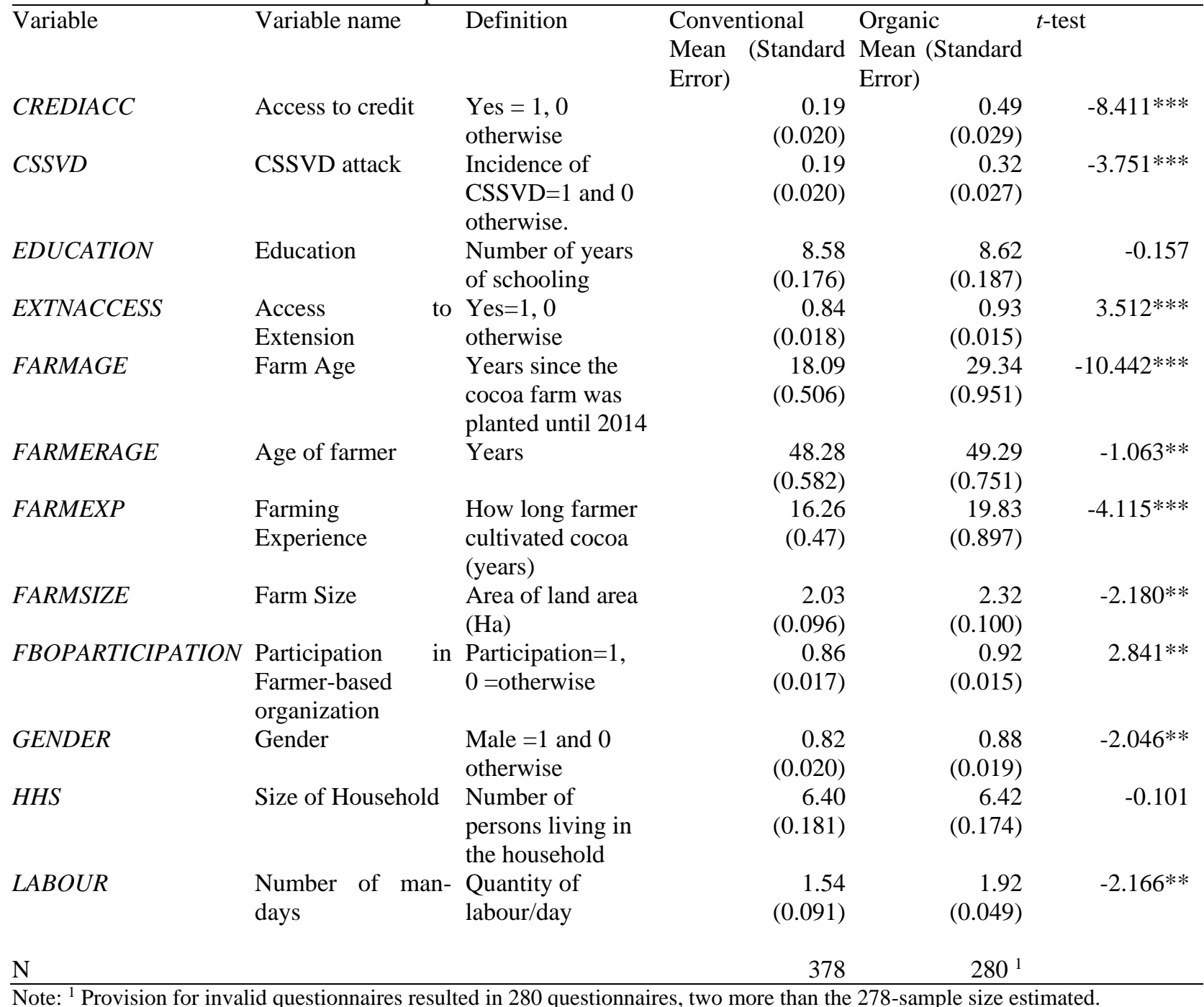


Beyond this, is to include the omitted variable (Greene, 2012; Asteriou and Hall, 2015). The approach of Apergis (2007) could not be followed because data on financial variables were not reliable. Due to the reasons adduced above, data on fertiliser and pesticides could not be included in the production function. Considering the omitted variable problem as part of the general misspecification problem, the power terms included in the test production function were considered as control variables for the misspecification (Ramsey, 1969; Asteriou and Hall, 2015). This raised another challenge; the sufficient condition that the sum of the coefficients of the cross terms in the translog production function, should be negative semi-definite, in the Ray (1998) SE formula (Equation 2), could not be met. Thus, for purposes of calculating the SE based on Ray (1998), the omitted variables problem is accommodated for the conventional model. It must be noted that Sherlund et al. (2002) and Rahman and Hasan (2008) have argued that omitted variables can inflate individual technical efficiency estimates. However, the random error, $v$, capture the errors including omitted variables (Aigner $\boldsymbol{e t}$ al, 1977; Mussa, 2014; Mujawariya et al., 2017; Njikam and Alhadji, 2017). Further, the use of farm age (age of trees) is a capital variable. Thus, we accommodate the omitted variables error on two grounds; the capture of the omitted variable error within the random error term and the fact the technical efficiency measure is not an ingredient in the calculation of scale efficiency. And finally, the role of FARMAGE as capital.

Table 2: Omitted variables test

\begin{tabular}{|c|c|c|}
\hline Description & $\begin{array}{l}\text { Conventional } \\
\chi^{2} \text { statistic }\end{array}$ & $\begin{array}{l}\text { Organic } \\
\chi^{2} \text { statistic }\end{array}$ \\
\hline $\begin{array}{l}H_{0} \text { Power terms are not jointly significant } \\
H_{1} \text { Power terms are jointly significant }\end{array}$ & $11.53 * * *$ & 1.77 \\
\hline Degrees of freedom & 2 & 2 \\
\hline Decision & Reject & Accept \\
\hline
\end{tabular}

Table 3: Functional form selection test

\begin{tabular}{|c|c|c|c|}
\hline & & Conventional & Organic \\
\hline$H_{0}$ : There is no technical inefficiency & OLS (Restricted) & -418.83696 & -231.04506 \\
\hline \multirow[t]{4}{*}{$H_{l}:$ There is technical inefficiency } & & -407.80759 & -213.53219 \\
\hline & $\begin{array}{l}\text { SFA- Cobb-Douglas } \\
\text { (Unrestricted) }\end{array}$ & & \\
\hline & Loglikelihood ratio & $22.05874 * *$ & $35.02654 * * *$ \\
\hline & Decision & Reject & Reject \\
\hline$H_{0}$ : There is no technical inefficiency & OLS (Restricted) & -376.22986 & -219.74919 \\
\hline \multirow[t]{4}{*}{$H_{l}$ : There is technical inefficiency } & & -367.43498 & -202.78204 \\
\hline & SFA- Translog (Unrestricted) & & \\
\hline & Loglikelihood ratio & $17.58976^{*}$ & $33.9343 * * *$ \\
\hline & Decision & Reject & Reject \\
\hline \multirow{5}{*}{$\begin{array}{l}H_{0} \text { : Cobb-Douglas is a better representation of the } \\
\text { data } \\
H_{1:} \text { Cobb-Douglas is not a better representation of the } \\
\text { data }\end{array}$} & SFA- Cobb-Douglas (Restricted) & -407.80759 & -213.53219 \\
\hline & & -367.43498 & -2002.78204 \\
\hline & SFA- Translog (Unrestricted) & & \\
\hline & Loglikelihood ratio & $80.74522 * * *$ & $21.5003^{* *}$ \\
\hline & Decision & Reject & Reject \\
\hline
\end{tabular}

Note: $* * *, * *, *$ denotes statistical significance at $1 \%, 5 \%$ and $10 \%$ respectively.

\section{Production function}

The estimations that generated results for technical efficiency of conventional and organic cocoa farms, required the testing of some hypotheses. First, the use of OLS is a better representation of the data than SFA. Second, that CD production function is preferred to the translog function. Third, that inefficiency is absent in the models. The results of the hypotheses tests are provided in Table 3. The rejection of the null hypotheses for both organic and conventional functions shows that there is technical inefficiency based on CD production function. Similarly, the rejection of the null hypotheses that there is no technical inefficiency in the translog production function is desirable. Comparing the CD to translog, the latter is preferred to the former. Further, the sigma squared values showed the existence of technical inefficiency in both the conventional and organic models. Aside from the empirical suitability of the translog SFA production function, estimating the SE by the Ray (1998) approach is conditioned on a translog functional form and existence of technical inefficiency. The marginal products (Table 5) generated from the selected production functions (Table 4) are positive in line with theoretical expectations. Both production practices show increasing returns to scale. Due to space limitations, technical inefficiency effects are not presented and discussed.

The production practices of organic and conventional cocoa production differ as noted earlier. Moreover, the computation of the scale efficiency measure relies on production function parameters which necessitate the estimation of separate production functions. The a priori estimation of the separate production functions hinges on these. 
Table 4: Estimation of production function and inefficiency effects

\begin{tabular}{|c|c|c|}
\hline Variables & Conventional & Organic \\
\hline \multirow[t]{2}{*}{ FARMAGE } & $1.5082 * * *$ & 0.0950 \\
\hline & $(0.5578)$ & $(0.5332)$ \\
\hline \multirow[t]{2}{*}{ FARMSIZE } & $0.9900 * * *$ & $0.9760 * *$ \\
\hline & $(0.3519)$ & $(0.4533)$ \\
\hline \multirow[t]{2}{*}{$L A B O U R$} & $2.2659 * * *$ & $1.1243 * * *$ \\
\hline & $(0.4463)$ & $(0.3447)$ \\
\hline \multirow[t]{2}{*}{ FARMAGE $E^{2}$} & $-0.2126 * * *$ & -0.0405 \\
\hline & $(0.0786)$ & $(0.0651)$ \\
\hline \multirow[t]{2}{*}{ FARMSIZE $E^{2}$} & $0.0455 * * *$ & -0.0220 \\
\hline & $(0.0051)$ & $(0.0782)$ \\
\hline \multirow[t]{2}{*}{$L A B O U R^{2}$} & $-0.2053 * * *$ & $-0.1188 * * *$ \\
\hline & $(0.0415)$ & $(0.0356)$ \\
\hline \multirow[t]{2}{*}{ FARMAGE*FARMSIZE } & 0.0405 & 0.1933 \\
\hline & $(0.08830$ & $(0.2331)$ \\
\hline \multirow[t]{2}{*}{ FARMAGE*LABOUR } & -0.1142 & 0.0871 \\
\hline & $(0.1474)$ & $(0.12580$ \\
\hline \multirow[t]{2}{*}{ FARMSSIZE*LABOUR } & $-0.2386^{*}$ & $-0.3263 * *$ \\
\hline & $(0.1312)$ & $(0.1286)$ \\
\hline \multirow[t]{2}{*}{ CONSTANT } & $-2.4015^{*}$ & 1.9335 \\
\hline & (1.4084) & $(1.2380)$ \\
\hline Sigma squared & $0.4291 * * *$ & $0.4650 * * *$ \\
\hline $\mathrm{N}$ & 378 & 280 \\
\hline Wald & $168.21 * * *$ & $85.4 * * *$ \\
\hline Loglikelihood & -367.4350 & -202.7820 \\
\hline
\end{tabular}

$* * *, * *, *$ are $1 \%, 5 \%$ and $10 \%$ levels of significance respectively. Figures in parenthesis are standard errors

Table 5: Elasticities and returns to scale

\begin{tabular}{lcc}
\hline & Conventional & Organic \\
\hline Land & 1.3994 & 0.0025 \\
Labour & 0.9147 & 0.6578 \\
Farm Age & 0.4448 & 0.4721 \\
Returns to scale & 1.2994 & 1.1324 \\
\hline
\end{tabular}

\section{Selection-bias}

The generation of the propensity scores from the binary choice model, and matching these for organic to conventional farms, resulted in new sub-samples of 161 organic and 161 conventional farms. The binary model estimation is reported and discussed in Djokoto et al. (2016). All other farms from the 658 were discarded. Matching after estimation of technical efficiency was performed following Rao et al. (2012), to avoid the influence of data attrition on technical efficiency estimation. For the discussion of the technical efficiency model, see Djokoto et al. (2017).

\section{Scale efficiency}

The mean SE for organic cocoa production is 0.5332 , corrected for selection bias, whilst a slightly higher value of 0.5351 was obtained with selection biased sample (Table 6). In the case of the conventional cocoa sample, the values are respectively 0.6601 and 0.6681 . In both cases, the mean values are less than 1 , indicating a suboptimal scale of operation. Indeed, the inspection of the individual farms showed that in both production practices, most farms operate at sub-optimal scale; 153 for organic and 151 for conventional (Table 7). The SE values less than 1 , in the presence of increasing returns to scale imply, the farms analysed failed to take advantage of the increasing returns-to-scale to increase their inputs for increased output (Karagiannis and Sarris, 2004). Our findings show a marked lower scale efficiency, indeed, quite pronounced SIE unlike studies on Africa (maize farms in Nigeria, 0.880 -Karimov et al., 2014) and rice in Ghana, 0.8200 (Anang and Rezitis, 2016). Since our findings relate to cocoa, we cautiously conclude that cocoa production is less scale efficient than other agricultural products. As scale economies are usually a consequence of the better and more efficient use of production factors, an increase in firm size first leads to higher marginal returns and lower marginal costs. Beyond a certain size, however, marginal returns will decrease, and marginal costs will rise although not contemporaneously. Optimal size is reached when marginal returns equal marginal costs.

Comparing organic and conventional SIE values, both production practices posted the same extreme values; 0.00 and 1.00. The mean for organic cocoa is 0.5332, significantly lower than that of conventional; 0.6601. This finding does not depart from that of Karagiannis et al. (2012) for dairy in Austria. This is irrespective of whether the complete sample is corrected for selection bias or not. Restrictions on types of resources and technology may be responsible for the higher scale inefficiency in organic 
production (IFOAM, 2008, 2014; Mayen et al., 2010; Beltran-Esteve and Reig-Martinez, 2014).

\section{Scale inefficiency effects}

Aside from the differences in SIE for the production practices, there exists variability within the SIE of each production practice (Table 7). We, therefore, investigated the drivers of this variability using fractional regression modelling. For conventional cocoa production (first panel of Table 8), the statistical significance of the RESET test statistic for logit, probit, loglog and cloglog suggest these functional forms are misspecified. Since the cauchit link function is the only well-specified link function, the next two tests for selecting the appropriate link function have become redundant. Therefore, the cauchit link function is selected. The second part of Table 8 on organic cocoa, presents an interesting situation. By the RESET test, all link functions are well specified except cloglog. Thus, the cloglog function is out of contention. By the GGOFF, all link functions are appropriate. For the one-to-one $P$-test, the null hypotheses that the loglog is preferred to logit, probit and cauchit link functions are rejected. Therefore, $\log \log$ link function is also out of consideration. Logit, probit, and cauchit link functions are indifferent to one another, based on the alternative hypothesis tests, thus any of these could be selected for discussion. However, only one of these could be used, thus we proceed to choose one. A close examination of the magnitudes of the test statistics for each of the link functions, as null hypotheses, shows that those of cauchit is the lowest. Thus, whilst all are indifferent, cauchit test statistics demonstrate 'strongest indifference' or non-rejection of the null hypothesis. Thus, the decision is in favour of the cauchit link function, for the organic SIE model.

Table 6: Scale efficiency

\begin{tabular}{|c|c|c|c|c|c|c|c|}
\hline & \multicolumn{3}{|c|}{ Conventional } & \multicolumn{3}{|c|}{ Organic } & \multirow{2}{*}{$\begin{array}{l}\text { Conventional- } \\
\text { Organic } \\
\text { Difference }\end{array}$} \\
\hline & $\mathrm{N}$ & SD & Mean & $\mathrm{N}$ & SD & Mean & \\
\hline Selection biased & 378 & 0.3106 & 0.6688 & 280 & 0.3690 & 0.5351 & $1.3519 * * *$ \\
\hline Non-selection biased & 161 & 0.3020 & 0.6601 & 161 & 0.3632 & 0.5332 & $0.1269 * * *$ \\
\hline Min & & & 0.00 & & & 0.00 & \\
\hline Max & & & 1.00 & & & 1.00 & \\
\hline
\end{tabular}

*** implies 1\% level of significance of the student's $t$ test. S.D.- standard deviation

Table 7: Optimality of scale efficiency

\begin{tabular}{lcc}
\hline Category & Organic & Conventional \\
\hline Supra-optimal & 0 & 0 \\
Optimal & 8 & 10 \\
Sub-optimal & 153 & 151 \\
$\mathrm{~N}$ & 161 & 161 \\
\hline
\end{tabular}

Table 8: Hypothesis tests for model selection for conventional and organic cocoa

\begin{tabular}{|c|c|c|c|c|c|}
\hline \multirow{2}{*}{\multicolumn{6}{|c|}{$\frac{\text { Logit }}{\text { Conventional cocoa production }}$}} \\
\hline & & & & & \\
\hline \multicolumn{6}{|c|}{ Ramsey test } \\
\hline RESET & $9.442 * * *$ & $8.961 * * *$ & $8.407 * * *$ & $9.461 * * *$ & 2.474 \\
\hline \multicolumn{6}{|c|}{ Goodness-of-functional form tests } \\
\hline GGOFF & $10.823 * * *$ & $11.678 * * *$ & $8.207 * * *$ & $9.946 * * *$ & 3.803 \\
\hline \multicolumn{6}{|l|}{$P$-test } \\
\hline $\mathrm{H}_{1 \text { Logit }}$ & - & $7.206 * * *$ & $9.902 * * *$ & $8.456 * * *$ & 0.755 \\
\hline $\mathrm{H}_{\text {Probit }}$ & $6.478 * * *$ & - & $10.144 * * *$ & $7.254 * * *$ & 0.747 \\
\hline $\mathrm{H}_{1 \log \log }$ & $6.063 * * *$ & $7.099 * * *$ & - & $5.056 * *$ & 0.778 \\
\hline $\mathrm{H}_{1 \mathrm{Clog} \log }$ & $12.227 * * *$ & $11.568 * * *$ & $12.533 * * *$ & - & 0.820 \\
\hline $\mathrm{H}_{1 \text { Cauchit }}$ & $13.982 * * *$ & $15.644 * * *$ & $18.626 * * *$ & $11.035^{* * *}$ & - \\
\hline \multicolumn{6}{|c|}{ Organic cocoa production } \\
\hline \multicolumn{6}{|c|}{ Ramsey test } \\
\hline RESET & 2.291 & 2.217 & 1.586 & $2.795^{*}$ & 2.281 \\
\hline \multicolumn{6}{|c|}{ Goodness-of-functional-form tests } \\
\hline GGOFF & 2.352 & 2.417 & 1.601 & 2.563 & 2.033 \\
\hline \multicolumn{6}{|l|}{$P$-test } \\
\hline $\mathrm{H}_{1 \text { Logit }}$ & - & 0.062 & $3.142 *$ & 0.611 & 0.024 \\
\hline $\mathrm{H}_{1 \text { Probit }}$ & 0.029 & - & $3.029 *$ & 0.216 & 0.004 \\
\hline $\mathrm{H}_{1 \log \log }$ & 1.029 & 0.987 & - & 0.815 & 0.281 \\
\hline $\mathrm{H}_{1 \mathrm{Clog} \log }$ & $4.251 * *$ & $4.596 * *$ & $5.445 * *$ & - & 1.901 \\
\hline $\mathrm{H}_{1 \text { Cauchit }}$ & 0.569 & 0.534 & $2.955^{*}$ & 0.064 & - \\
\hline
\end{tabular}

Note: $* * * * * * *$ denotes statistical significance at $1 \%, 5 \%$ and $10 \%$ respectively. 
Table 9: Hypothesis tests for model selection for the combined sample

\begin{tabular}{|c|c|c|c|c|c|}
\hline & Logit & Probit & Loglog & Cloglog & Cauchit \\
\hline \multicolumn{6}{|c|}{ Ramsey test } \\
\hline RESET & $2.916^{*}$ & $3.277^{*}$ & $4.307 *$ & 2.583 & 1.854 \\
\hline \multicolumn{6}{|c|}{ Goodness-of-functional-form tests } \\
\hline \multicolumn{6}{|c|}{ GGOFF } \\
\hline$P$-test & 3.788 & 3.968 & 4.398 & 2.384 & 3.498 \\
\hline $\mathrm{H}_{1 \text { Logit }}$ & - & $4.129 * *$ & $5.279 * *$ & $1 / 188$ & 1.108 \\
\hline $\mathrm{H}_{1 \text { Probit }}$ & $3.572 *$ & - & $4.941 * *$ & 1.517 & 0.926 \\
\hline $\mathrm{H}_{1 \log \log }$ & 2.495 & 2.682 & - & 1.031 & 0.442 \\
\hline $\mathrm{H}_{1 \mathrm{Clog} \log }$ & $3.348 *$ & $4.330 * *$ & $5.976 * *$ & - & 0.223 \\
\hline $\mathrm{H}_{1 \text { Cauchit }}$ & $6.086 * *$ & $6.376 * *$ & $7.285 * * *$ & $3.829 *$ & - \\
\hline
\end{tabular}

Note: $* * *, * * *$ denotes statistical significance at $1 \%, 5 \%$ and $10 \%$ respectively.

Table 10: Scale inefficiency effects

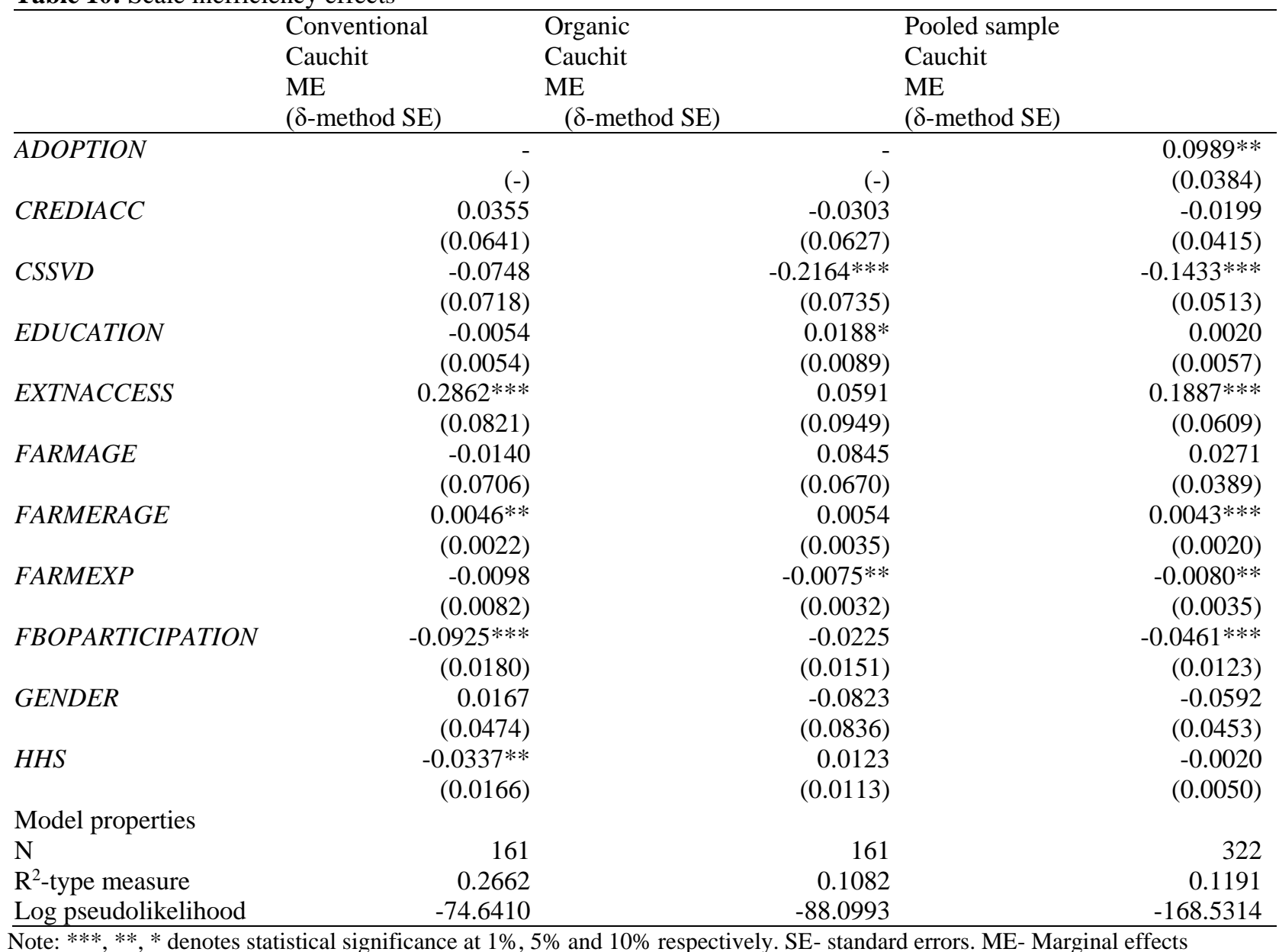

For the combined sample (Table 9), the RESET test statistics for logit, probit and loglog are statistically significant. This implies these link functions are misspecified whilst the other two; cloglog and cauchit are not. The earlier three link functions are therefore eliminated from consideration. Using the cloglog as a null hypothesis with cauchit as the alternative hypothesis, the cloglog is rejected in favour of the cauchit link function. Consequently, the marginal effects for conventional, organic and combined sample for the cauchit link function are presented in Table 10.

The $\mathrm{R}^{2}$ measures appear low. However, these are the highest among the five link functions and the best attainable, as the OLS estimates; the default posted values lower than these. Moreover, as the $\mathrm{R}$ squared-type measure is a relative measure unlike the standard Rsquared value, the absolute value is less important, rather how this compares to those of competing functional forms (Ricci, 2010; Ricci and Martinez, 2008; Wei Shi, 2018). The positive marginal effect of ADOPTION, 0.0989 indicates organic cocoa producers are less scale efficient than conventional cocoa producers. This finding from a multivariate analysis confirms the outcomes of the univariate analysis of the previous section. The existence of CSSVD enhances scale efficiency. CREDIACC should allow farmers to acquire resources to increase input levels thereby increasing the scale of operation. This may appear to be the case for the conventional cocoa producers. However, the marginal effect of CREDIACC for both organic and the combined sample showed negative signs. 
Since in all three models, the magnitude for the CREDIACC is statistically insignificant, CREDIACC does not have any discernible effect on scale efficiency. Wongnaa and Awunyo-Vitor (2019) however found a positive effect of credit on scale efficiency.

The role of CSSVD on SE is rather interesting. CHED, the Ghana Cocoa Board agency that addresses issues of the disease, undertakes disease control programmes involving cutting and burning of diseased trees. This does not reduce land area but number trees, lower labour use for husbandry practices as well as output. By this, the levels of input, for example, a lower level of labour leads to reduced output. This then culminates in the appropriate scale of operation. Formal education had no discernible effect on SIE for conventional cocoa and the combined sample, consistent with the conclusions of Paul $\boldsymbol{e t}$ al. (2004) and Rahman and Awerije (2015). However, formal education increased SIE for organic cocoa producers. Formally educated farmers may be motivated to cultivate larger farms, however, they engage in other livelihoods, which compete with organic cocoa production, may lead to less attention given to the organic cocoa farm. Thus, the input and output results may be inappropriate for the chosen farm size. The findings of Wongnaa and Awunyo-Vitor (2019) for conventional maize in Ghana, concurs with the findings of this study.

EXTNACCESS strongly reduced SE. This finding is surprising, as access to extension should improve farm management skills and capacity of farmers. This notwithstanding, Madau (2015) and Paul et al. (2004) reported a neutral effect whilst Anang et al. (2016) and Wongnaa and Awunyo-Vitor (2019) reported a positive effect. The age of the farm (FARMAGE) has no discernible effect on scale inefficiency for all three models. Gimbol et al. (1994) and Currey et al. (2007) acknowledged the parabolic distribution of the output of cocoa over time. Thus, with the relatively aged farms noted in Table 1, the output will decline irrespective of increased input use. This explains the positive sign of the coefficient of the FARMAGE. However, the effect is not strong enough to result in a statistically significant value of the marginal effect. Farmer age (FARMERAGE) exacerbates SIE for the conventional and combined sample. As cocoa farmers age, their inability to pay attention to the cocoa farms result in absenteeism and sometimes, turning the farm over to caretakers, who may not provide adequate attention, thereby failing to ensure the appropriate scale of operation. The conclusions of Wongnaa and Awunyo-Vitor (2019) for maize confirms these findings.

The coefficient of FARMEXP has a negative sign for all three models. Increased experience in cocoa farming should lead to accumulation of knowledge resulting in a better combination of input and their levels relative to farm size. Therefore, farm experience enhances scale efficiency. The effect was however significant for the organic sample and the combined sample but not so for the conventional sample. For Rahman and Awerije (2015) and Wongnaa and Awunyo-Vitor (2019), farmer experience enhanced scale efficiency. Membership and participation in FBO, whilst providing the platform to receive knowledge and acquire skills from subject matter specialists, it also provides opportunities to network, share ideas and communicate at the level of peers. This creates the platform to deliberate on common problems to find solutions. This is useful in enhancing scale efficiency (Wongnaa and Awunyo-Vitor, 2017), thus, it is no wonder that FBOPARTICIPATION enhances SE. Gender does not distinguish SIE of OA and CA, in all three cases, whilst HHS promotes SE for conventional cocoa. Increased $H H S$ provides opportunity for more labour that can be combined with land, to maintain an appropriate farm scale. This finding agrees with the recent findings of Wongnaa and Awunyo-Vitor (2019).

\section{CONCLUSIONS}

In this study, we departed from the existing SE literature in three ways: We accounted for selection-bias in the organic and conventional samples. We modelled parametrically estimated SE, using fractional regression and empirically selected the appropriate link function and considered an institutional variable, participation in farmer-based organisations.

Both organic and conventional producers are scale inefficient. However, organic producers' mean SE of 0.5332 is significantly less than 0.6601 , for conventional producers, thus OA is not more scale efficient than CA. Although it is recommended that both producer groups improve SE, organic producers require greater work to do to make up for the almost $50 \%$ SIE. Until the organic regulators increase the latitude for resources to be used in production, organic agriculture researchers must come up with quality inputs whilst organic producers need to improve their capacity in farm management, to improve input allocation on the farm. SE in organic cocoa can be further increased through increased efforts by CHED to control CSSVD. Younger persons should be encouraged to go into and remain in cocoa production. Revenue side factors such as increased producer price as well as cost side factors including availability of cost-effective production inputs, leading to improved profitability, could be useful. Organic cocoa producers should increase farm hectares to reduce SIE. Farmer-based organisations should be further strengthened, particularly focusing on activities that will increase participation.

\section{REFERENCES}

ABEKOE, M. K., OBENG-OFORI, D. \& EGYIR, I. S. (2002). Technography of cocoa in the forest zone of Ghana. Unpublished Technical Report, Convergence of Sciences Project. University of Ghana, Legon, 51 pp.

AIGNER, D., LOVELL, C. A. L., \& SCHMIDT, P. (1977). Formulation and estimation of stochastic frontier production function models. Journal of Econometrics, 6(1): 21-37. https://doi.org/10.1016/0304-4076(77)90052-5

ANANG, B., \& REZITIS, A. (2016). Does farm size matter? Investigating scale efficiency of peasant rice farmers in northern Ghana. Economics Bulletin, 36(4): 2275-2290. https://doi.org/10.1016/j.foodpol.2018.10.007 
APERGIS, N. (2007). Old wine in a new bottle: are financial variables omitted variables in the production function? https://doi.org/10.2139/ssrn.994141

ASTERIOU, D., \& HALL, S. G. (2015). Applied Econometrics. Palgrave Macmillan.

AYENOR, G. K., RÖLING, N. G., PADI, B., VAN HUIS, A., OBENG-OFORI, D., \& ATENGDEM, P. B. (2004). Converging farmers' and scientists' perspectives on researchable constraints on organic cocoa production in Ghana: results of a diagnostic study. NJAS-Wageningen Journal of Life Sciences, 52(3),

261-284. https://doi.org/10.1016/s1573-5214(04)80017-4

BARAN, J. (2013). Efficiency of the production scale of polish dairy companies based on data envelopment analysis. Acta Scientiarum Polonorum Oeconomia, 12(2): 5-13.

BELTRÁN-ESTEVE，M., \& REIG-MARTÍNEZ, E. (2014). Comparing conventional and organic citrus grower efficiency in Spain. Agricultural Systems 129, 115-123. https://doi.org/10.1016/j.agsy.2014.05.014

BREMMER, J., LANSINK, A. G. O., \& HUIRNE, R. B. (2008). The impact of innovation, firm growth and perceptions on technical and scale efficiency. Agricultural Economics Review, 9(2): 6585.

CAMERON, A. C. \& TRIVEDI, P. K. (2013). Regression analysis of count data (Vol. 53). Cambridge university press.

CURREY, G. N., KOCZBERSKI, G., OMURU, E. \& NAILINA, R. S. (2007). Farming or foraging? Household labour and livelihood strategies amongst smallholder cocoa growers in Papua New Guinea. Black Swan Press, Curtin University of Technology, GPO Box U1987, Perth WA 6845.

DAVIDSON, R., \& MACKINNON, J. G. (1981). Several tests for model specification in the presence of alternative hypotheses. Econometrica, 49, 781-793. https://doi.org/10.2307/1911522

DJOKOTO, J. G. (2016). Ghanaian fair-trade cocoaproducing households' livelihood diversification and efficiency, International Journal of Green Economics, 10(2): 191-212. https://doi.org/10.1504/ijge.2016.10001588

DJOKOTO, J. G., OWUSU, V., \& AWUNYO-VITOR, D. (2016). Adoption of organic agriculture: Evidence from cocoa farming in Ghana. Cogent Food \& Agriculture, 2(1):

1242181 . https://doi.org/10.1080/23311932.2016.1242181

DJOKOTO, J. G., OWUSU, V., \& AWUNYO-VITOR, D. (2017). Technical efficiency in organic and conventional agriculture - A gender comparison. Review of Agricultural and Applied Economics, 20(2), 3-11.

GIMBOL, K. C., BATTESE, G. E. \& FLEMING, E. M. (1994). Technical efficiencies of smallholder cocoa producers in Papua New Guinea: A stochastic frontier analysis. In 1994 Conference (38th): February 8-10, 1994, Wellington, New Zealand (No. 148217). Australian Agricultural and Resource Economics Society.

GREENE, W. (2012). Econometric Analysis (international edition) Pearson. Edinburgh Gate, Harlow, Essex CM20 2JE, England.

GUESMI, B., SERRA, T., KALLAS, Z., \& ROIG, J. G. (2012). The productive efficiency of organic farming: the case of grape sector in Catalonia. Spanish Journal of Agricultural Research, 10(3): 552-566. https://doi.org/10.5424/sjar/2012103-462-11

IFOAM (International Federation of Organic Agricultural Movements) (2008). Definition of organic agriculture. http://www.ifoam.org/growing_organic/definitions/do a/index.html

IFOAM (International Federation of Organic Agricultural Movements) 2014. Definition of organic agriculture. http://www.ifoam.org/growing_organic/definitions/do a/index.html

IMBENS, G. W. (2004). Nonparametric estimation of average treatment effects under exogeneity: A review. Review of Economics and Statistics, 86(1): 4-29. https://doi.org/10.3386/t0294

KARAGIANNIAS, G., SALHOFER, K., \& SINABELL, F. (2012, June). Scale efficiency in organic and conventional dairy farming. In First Italian Association of Agricultural and Applied Economics Congress, Trento, Italy (pp. 4-5).

KARAGIANNIS, G., \& MELFOU, K. (2015). Technical and scale efficiency of PGI bean farms in Greece. In Research for Rural Development. International Scientific Conference Proceedings (Latvia). Latvia University of Agriculture.

KARAGIANNIS, G., \& SARRIS, A. (2004). A Comparison of SFA and DEA Scale Efficiency Estimates: The Case of Greek Fresh Fruits Producers. Indian Economic Review, 149-168.

KARAGIANNIS, G., \& SARRIS, A. (2005). Measuring and explaining scale efficiency with the parametric approach: the case of Greek tobacco growers. Agricultural Economics, 33(s3): 441-451. https://doi.org/10.1111/j.1574-0864.2005.00084.X

KARIMOV, A., AWOTIDE, B. A., \& TIMOTHY AMOS, T. (2014). Production and scale efficiency of maize farming households in South-Western Nigeria. International Journal of Social Economics, 41(11): $\quad$ 1087-1100. https://doi.org/10.1108/ijse-12-2012-0260

KELLY, E., SHALLOO, L., GEARY, U., KINSELLA, A., THORNE, F., \& WALLACE, M. (2013). An analysis of the factors associated with technical and scale efficiency of Irish dairy farms. International Journal of Agricultural Management, 2(3): 149-159. https://doi.org/10.5836/ijam/2013-03-04

KUMBHAKAR, S. C. \& LOVELL, C. A. K. (2000). Stochastic Frontier Analysis, Cambridge University Press, Cambridge. https://doi.org/10.1007/0-38725895-7 9

LAKNER, S. \& BREUSTEDT, G. (2016). Productivity and technical efficiency of organic farming-A literature survey. Acta Fytotechnica et Zootechnica, 18(5):

74-77. https://doi.org/10.15414/afz.2015.18.si.74-77

MADAU, F. A. (2007). Technical efficiency in organic and conventional farming: Evidence from Italian cereal farms. Agricultural Economics Review, 8(1): 5- 
21. https://doi.org/10.1016/s0306-9192(01)00007-0

MADAU, F. A. (2011). Parametric estimation of technical and scale efficiencies in Italian citrus farming Agricultural Economics Review, 12(1): 91-111

MAYEN, C. D., BALAGTAS, J. V., \& ALEXANDER, C. E. (2010). Technology adoption and technical efficiency: Organic and conventional dairy farms in the United States. American Journal of Agricultural Economics, $92(1)$ :

181-195. https://doi.org/10.1093/ajae/aap018

MEEUSEN W., \& VAN DEN BROECK, J. (1977). Efficiency estimation from Cobb-Douglas production functions with composed error. International Economic Review, 18(2): 435-444. https://doi.org/10.2307/2525757

MGENI, D., \& HENNINGSEN, A. (2012). Productivity, Efficiency, and Competitiveness of Small-Scale Organic Cotton Production in Tanzania. In AsiaPacific Productivity Conference.

MUSSA, R. (2014). Externalities of education on efficiency and production uncertainty of maize in rural Malawi. http://mpra.ub.uni-muenchen.de/54628/

NJIKAM, O., \& ALHADJI, H. A. (2017). Technical efficiency among smallholder rice farmers: a comparative analysis of three agro-ecological zones in Cameroon. African Development Review, 29(1): 2843. https://doi.org/10.1111/1467-8268.12236

OUDE LANSINK, A., PIETOLA, K. \& BÄCKMAN, S., (2002). Efficiency and productivity of conventional and organic farms in Finland 1994-1997. European Review of Agricultural Economics, 29(1): 51-65. https://doi.org/10.1093/erae/29.1.51

PAGAN, A., \& VELLA, F. (1989). Diagnostic tests for models based on individual data: a survey. Journal of Applied Econometric, 4, S29-S59. https://doi.org/10.1002/jae.3950040504

PANTZIOS, C., ROZAKIS, S., \& TZOUVELEKAS, V. (2002). Assessing the perspectives of EU cotton farming: technical and scale efficiencies of Greek cotton growers. Paper prepared for presentation at the Xth EAAE Congress 'Exploring Diversity in the European Agri-Food System', Zaragoza (Spain): 2831 August 2002

PAPKE, L. E., \& WOOLDRIDGE, J. M. (1996). Econometric methods for fractional response variables with an application to 401(k) plan participation rates. Journal of Applied Economics, 11, 619-632. https://doi.org/10.3386/t0147

PAUL, C., NEHRING, R., BANKER, D., \& SOMWARU, A. (2004). Scale economies and efficiency in US agriculture: are traditional farms history? Journal of Productivity Analysis, 22(3): 185-205. https://doi.org/10.1007/s11123-004-7573-1

PAULL, J. (2013). A history of the organic agriculture movement in Australia. In Organics in the global food chain (pp. 37-61). Connor Court Publishing.

PONISIO, L. C., M'GONIGLE, L. K., MACE, K. C., PALOMINO, J., DE VALPINE, P., \& KREMEN, C. (2015, January). Diversification practices reduce organic to conventional yield gap. In Proceedings of the Royal Society of $B$ (Vol. 282, No. 1799, p. 20141396). The Royal Society. https://doi.org/10.1098/rspb.2014.1396

POUDEL, K. L., JOHNSON, T. G., YAMAMOTO, N., GAUTAM, S., \& MISHRA, B. (2015). Comparing technical efficiency of organic and conventional coffee farms in rural hill region of Nepal using data envelopment analysis (DEA) approach. Organic Agriculture, 5(4):

263-275.

https://doi.org/10.1007/s13165-015-0102-x

RAHMAN, S., \& AWERIJE, B. O. (2015). Technical and scale efficiency of cassava production system in Delta State, Nigeria: an application of Two-Stage DEA approach.Journal of Agriculture and Rural Development in the Tropics and Subtropics (JARTS): 116(1): 59-69.

RAHMAN, S., \& HASAN, M. K. (2008). Impact of environmental production conditions on productivity and efficiency: A case study of wheat farmers in Bangladesh. Journal of Environmental Management, 88(4): 1495-1504. https://doi.org/10.1016/j.jenvman.2007.07.019

RAMALHO, E. A., RAMALHO, J. J., \& MURTEIRA, J. M. (2011). Alternative estimating and testing empirical strategies for fractional regression models. Journal of Economic Surveys, 25, 19-68. https://doi.org/10.1111/j.1467-6419.2009.00602.x

RAMALHO, E. A., RAMALHO, J. J., \& MURTEIRA, J. M. (2014). A generalized goodness-of-functional form test for binary and fractional regression models. The Manchester School, 82, 488-507. https://doi.org/10.1111/manc.12032

RAMALHO, E. A., RAMALHO, J. J. S. \& HENRIQUES, P. D. (2010). Fractional regression models for second stage DEA efficiency analyses. Journal of Productivity Analysis 34, 239-255. https://doi.org/10.1007/s11123-010-0184-0

RAMALHO, J. J., \& DA SILVA, J. V. (2013). Functional form issues in the regression analysis of financial leverage ratios. Empirical Economics, 44(2): 799-831. https://doi.org/10.1007/s00181-012-0564-6

RAMALHO, J. J. S. (2013). FRM: Stata module to estimate and test fractional regression models, statistical software components 457542, Boston College Department of Economics.

RAMSEY, J. B. (1969). Tests for specification errors in classical linear least-squares regression analysis. Journal of the Royal Statistical Society, Series B 31(2): 350-371. 6161.1969.tb00796.x

https://doi.org/10.1111/j.2517-

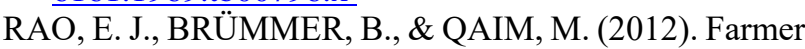
participation in supermarket channels, production technology, and efficiency: the case of vegetables in Kenya.American Journal of Agricultural Economics, 94(4): $\quad$ 891-912. https://doi.org/10.1093/ajae/aas024

RAY, S. C. (1998). Measuring scale efficiency from a translog production function. Journal of Productivity Analysis, 11(2): 183-194.

RICCI, L. (2010). Adjusted R-squared type measure for exponential dispersion models. Statistics \& Probability Letters, 80(17-18): 1365-1368.

RICCI, L., \& MARTÍNEZ, R. (2008). Adjusted R2-type measures for Tweedie models. Computational 
Statistics \& Data Analysis, 52(3): 1650-1660.

ROSENBAUM, P. R., \& RUBIN, D. B. (1983). The central role of the propensity score in observational studies for causal effects. Biometrika, 70(1): 41-55. https://doi.org/10.21236/ada114514

SENGUPTA, A., \& KUNDU, S. (2006). Scale efficiency of Indian farmers: A non-parametric approach. Indian Journal of Agricultural Economics, 61(4): 677-687.

SHERLUND, S. M., BARRETT, C. B., \& ADESINA, A. A. (2002). Smallholder technical efficiency controlling for environmental production conditions. Journal of Development Economics, 69(1) 85-101. https://doi.org/10.2139/ssrn.329661

TIEDEMANN, T., \& LATACZ-LOHMANN, U. (2013). Production risk and technical efficiency in organic and conventional agriculture-the case of arable farms in Germany. Journal of Agricultural Economics, 64(1): 73-96. https://doi.org/10.1111/j.14779552.2012.00364.x

TZOUVELEKAS, V., PANTZIOS, C. J., \& FOTOPOULUS, C. (2002). Technical efficiency of alternative farming systems: the case of Greek organic and conventional olive-growing farms. Food Policy, 26(6): 549-69. $\quad$ https://doi.org/10.1016/s0306$\underline{9192(01) 00007-0}$
WATKINS, K. B., HRISTOVSKA, T., MAZZANTI, R., WILSON JR, C. E., \& SCHMIDT, L. (2014). Measurement of technical, allocative, economic, and scale efficiency of rice production in Arkansas using data envelopment analysis. Journal of Agricultural and Applied Economics, 46(1): 89-106. https://doi.org/10.1017/s1074070800000651

WEI SHI, S. (2018). Crowdfunding: Designing an effective reward structure. International Journal of Market Research, 60(3): 288-303.

WONGNAA, A. C., \& AWUNYO-VITOR, D. (2019). Scale efficiency of maize farmers in four agro ecological zones of Ghana: A parametric approach. Journal of the Saudi Society of Agricultural Sciences. $\quad$ 18(3): 275-287. https://doi.org/10.1016/j.jssas.2017.08.003

YGL (2008). Yayra Glover Limited. http://yayraglover.com/index.php/company-profile

YGL (2013). Information available from Yayra Glover Limited. http://yayraglover.com/. 